\title{
Pearson Correlation based Approach for Estimating the Association between Energy Consumption and Households' Characteristics in Residential Buildings
}

\author{
Dr. Anisha Noori Kakon ${ }^{1}$ and Farhadur Reza ${ }^{2^{*}}$ \\ ${ }^{1}$ Associate Professor, Department of Urban and Regional Planning, \\ Jahangirnagar University, Savar, Bangladesh \\ ${ }^{2}$ Assistant Professor, Department of Urban and Regional Planning, \\ Jahangirnagar University, Savar, Bangladesh \\ ${ }^{1}$ kakon_urp@yahoo.com, ${ }^{2}$ farhadrezaurp@juniv.edu
}

\begin{abstract}
The purpose of this paper is to analyze the association of energy consumption with households' characteristics of residential buildings in Dhaka city, Bangladesh. Pearson correlation has been employed in this study as correlation among variables allows the researchers to explore the relationship between two or more variables at a time and provides an indication of the direction as well as measure the strength of relationship among the variables studied. Energy consumption data are collected from households' monthly electricity bill charged by Dhaka Electricity Supply Company while socioeconomic characteristics and building features were obtained through household interview and measurement of buildings' floor and window dimensions respectively. Results indicate that, energy consumption has a strong positive relation with households' number of appliances, monthly income and flat size rather than households' member.
\end{abstract}

Keywords: Pearson correlation, building geometry, energy consumption, socioeconomic variables, residential building

\section{Introduction}

Over the last century the world is becoming predominantly urban [1]. Half of the world's population lives in cities, which tend to reach 70 per cent in 2050 [2]. Cities are nodes of consumption, depend utterly on a constant flow of materials and energy from around the world in order to function [3]. They consume about 75 per cent of global primary energy and emit between 50 and 60 per cent of the world's total greenhouse gases [4]. A large number of new buildings are constructed in the process of urbanization which leads to massive building energy consumption during operation period [5]. Energy consumption in developing countries is predicted to rise up over 85 per cent of the total increasing by 2040 due to economic rise and population growth [6]. Currently residential and commercial buildings of urban area consume approximately 60 per cent of the world's energy [7]. Energy services in buildings like the provision of thermal comfort, refrigeration, illumination, communication, entertainment, sanitation and hygiene, nutrition, as well as other amenities are responsible for a significant share of electricity use worldwide [8].

Residential buildings accounts for over one-third of the total final energy consumption globally [6]. The situation in Dhaka is no different; where almost 55 per cent of total generated energy is consumed [12]. The energy consumption of Dhaka has almost doubled between 2005 and 2011 and at present 50 percent of total generated energy is

Received (January 5, 2017), Review Result (March 10, 2018), Accepted (March 14, 2018)

* Corresponding Author 
consumed by residential sector [14]. Load shedding has increased, as the demand of electricity continues to exceed supply, especially during the summer months when it is hot and humid thus creating discomfort and making people to use more cooling appliances [13]. This study, therefore, is an endeavor to analyze residential building energy consumption considering building geometry and socio-economic issues in Dhaka city.

\section{Literature Review}

Though literatures on energy consumption in residential buildings are extensively available in the context of developed countries, these studies are very limited in developing countries [10]. Liu and Kojima [11] conducted a study on energy consumption in different types of buildings in different cities of China considering building structure forms, floor area, year of construction, window area were considered as building characteristics and number of children as social characteristics. Study results show that bigger window size in high-rise building made better thermal comfort and thus lower the scale of energy use. On the other hand, energy consumption increases with the number of children increases in households. Study conducted by Touchie, Binkley and Pressnail [9] found no relation between building height or size with energy use. However, fenestration ratio and boiler efficiency of the building possess strong relationship with energy use. Strømann-Andersen and Sattrup [17] found that urban canyon play a vital role in building energy consumption both in office and residential buildings. UNHABITAT [15] identified that, household electricity consumption depends on income, climate, using low-efficiency appliances, size of the dwelling, user energy consciousness and the cost of electricity. Air conditioning is also increasingly contributing to household electricity consumption, in urban areas of both developed and developing countries. Bahauddin, Rahman and Ahmed [16] stated that, the present planning and building laws mainly focuses on the density and development control related issues and not on the energy consequences of urban and building development practices. There are no regulations for the building envelope, materials or energy performance of a building. In addition, narrow setbacks do not allow ample daylight into the interior spaces of a building, therefore is resulting in the use of artificial lighting even in daytime. Ahsan, Soebarto and Williamson [10] examined the effects of building design and household characteristics on the energy use in high-rise residential buildings of Dhaka. Results showed that, window area, household size and number of air conditioner positively affect the buildings' energy use. However, an increase in window-to-floor area ratio decreases energy consumption. This study did not consider other issues like household income, number of households' appliances which are critical in analyzing energy consumption. Chowdhury, Alam and Paul [20] in their study attempted to determine the optimum window location to increase daylight performance and thus reduce energy consumption in residential buildings of Dhaka.

\section{Methodology}

\subsection{Fundamental Concept of Pearson's Correlation}

Correlation is widely used for assessing the relationship between variables. Pearson's correlation coefficient is used to express the strength of the relationship. This coefficient is generally used when variables are of quantitative nature, that is, ratio or interval scale variables.

Pearson's correlation coefficient is denoted by $r$ and is expressed as 


$$
r=\frac{\sum x y-\sum x \sum y}{\sqrt{\left\{n \sum x^{2}-\left(\sum x\right)^{2}\right\}\left\{n \sum y^{2}-\left(\sum y\right)^{2}\right.}}
$$

The value of $r$ always lies between -1 and 1 inclusive, that is, $-1 \leq \mathrm{r} \leq 1$. If $\mathrm{Y}$ increases when $\mathrm{X}$ increases, it is said that there is positive or direct correlation between them. However, if $Y$ decreases when $X$ increases (or vice versa), then it implies that they are negatively or inversely correlated. The extreme values of $r$, that is, when $r= \pm 1$, indicate that there is perfect (positive or negative) correlation between $\mathrm{X}$ and $\mathrm{Y}$. However, if $\mathrm{r}$ is 0 , implies that there is no or zero correlation [25].

\subsection{Data}

Interview was carried out by structured questionnaire to obtain data on household size, monthly income, type and number of appliances they use. Energy consumption data were collected from household's monthly electricity bill (from January, 2016 to December, 2016) charged by Dhaka Electricity Supply Company (DESCO). Measurement was taken in sampled dwelling units to determine flat size and window area. Fiberglass Tape Measure was used to measure window and floor dimensions. Photographs were taken to demonstrate buildings' geometric features. Socio-economic interview and measurement of building geometry features were accomplished in 141 sample households of Dhaka city. In addition, data on energy ratings of appliances and thermal properties of window were collected from different relevant literature.

\subsection{Analytical Method}

A number of scholars' research indicate that building geometric variables such as floor level, floor size, window size, window wall ratio, window floor ratio and socio-economic variables like household size and income have significant effect on energy consumption [11,12, 13 and 14]. The aim of this study was to investigate the relationship between energy consumption and other variables namely household member, income, number of appliances, flat size and window area. All these variables are quantitative and continuous in nature. Initially, average monthly energy consumption data in respect with households' variables were presented to portray a general scenario. Then, relationship between energy consumption and households' characteristics was estimated applying Pearson Correlation. To examine the relationship between two or more quantitative and continuous variables at a time researchers widely exploit correlation between variables. Besides, this also provides an indication of both the direction either positive or negative and measure the strength or degree of relationship among the variables studied [18 and 19]. Therefore, Pearson Correlation method was used to explore the association between energy consumption and households' characteristics. Statistical Package for Social Science (SPSS) software, version 16 was employed for data analysis.

\section{Results and Discussion}

\subsection{Profile of the Households}

Maximum households' income belong BDT 71,000-80,000 per month followed by BDT 41,000-50,000 and BDT 21,000-30,000 per month. The lowest slab of households' income ranges from BDT 81,000-90,000 followed by BDT more than 100,000 and BDT $10,000-20,000$ per month. Majority of the households are composed of four members 
followed by five members. Least number of households are of one and more than 7 members (Table 1).

Table 1. Socio-economic and Building Geometric Features of Households

\begin{tabular}{|c|c|c|c|c|c|}
\hline \multicolumn{3}{|c|}{ Households' Income } & \multicolumn{3}{|c|}{ Households' Member } \\
\hline $\begin{array}{c}\text { Income }(B D T \\
\text { per Month })\end{array}$ & Frequency & Percentage & $\begin{array}{c}\text { Household } \\
\text { Member }\end{array}$ & Frequency & Percentage \\
\hline $10000-20000$ & 10 & 7.09 & 1 & 1 & 0.71 \\
\hline $21000-30000$ & 19 & 13.48 & 2 & 8 & 5.67 \\
\hline $31000-40000$ & 14 & 9.93 & 3 & 17 & 12.06 \\
\hline $41000-50000$ & 19 & 13.48 & 4 & 47 & 33.33 \\
\hline $51000-60000$ & 14 & 9.93 & 5 & 44 & 31.21 \\
\hline $61000-70000$ & 16 & 11.35 & 6 & 18 & 12.77 \\
\hline $71000-80000$ & 20 & 14.18 & 7 and more & 6 & 4.26 \\
\hline $81000-90000$ & 3 & 2.13 & Total & 141 & 100 \\
\hline $91000-100000$ & 17 & 12.06 & \multicolumn{3}{|c|}{ Households' Flat Size } \\
\hline $\begin{array}{c}100000 \text { and } \\
\text { more }\end{array}$ & 9 & 6.38 & $\begin{array}{c}\text { Flat Size } \\
\left(\mathrm{m}^{2}\right)\end{array}$ & Frequency & Percentage \\
\hline Total & 141 & 100 & 54 and less & 12 & 8.51 \\
\hline \multicolumn{3}{|c|}{ Households' Window Area } & $55-71$ & 23 & 16.31 \\
\hline $\begin{array}{c}\text { Window Area } \\
\left(\mathrm{m}^{2}\right)\end{array}$ & Frequency & Percentage & $72-89$ & 20 & 14.18 \\
\hline 4.5 and less & 11 & 7.8 & $90-107$ & 32 & 22.70 \\
\hline $4.6-9$ & 51 & 36.17 & $108-125$ & 27 & 19.15 \\
\hline $9.1-13.5$ & 45 & 31.91 & $126-143$ & 18 & 12.77 \\
\hline $13.6-18$ & 17 & 12.06 & 144-161 & 3 & 2.13 \\
\hline 18 and more & 17 & 12.06 & $\begin{array}{c}162 \text { and } \\
\text { more }\end{array}$ & 6 & 4.26 \\
\hline Total & 141 & 100 & Total & 141 & 100 \\
\hline
\end{tabular}

Most of the flats range from 90 to $107 \mathrm{~m}^{2}$ followed by 108 to $125 \mathrm{~m}^{2}$ in size. Flat size of 55 to $71 \mathrm{~m}^{2}$ and 72 to $89 \mathrm{~m}^{2}$ are also noticeable. Maximum flats' window area lies between 4.6 to $9 \mathrm{~m}^{2}$ and 9.1 to $13.5 \mathrm{~m}^{2}$. Flats with window area of 13.6 to $18 \mathrm{~m}^{2}$ and more than $18 \mathrm{~m}^{2}$ are noteworthy and few flats are with window area of 4.5 and less than $4.5 \mathrm{~m}^{2}$.

\subsection{Households' Appliances}

Appliance profile (Table 2) indicates that, fan and light are used by all the households and television, refrigerator and mobile phone also more commonly used appliances. Besides, percentages of households having desktop and laptop computer, microwave woven, freezers and air conditioners are noteworthy. Among the appliances light, fan and mobile phone are found maximum in number per household and the number of other appliances is one per household. Energy rating of the appliances suggests that air conditioner $(2250 \mathrm{w})$, washing machine $(1500 \mathrm{w})$, microwave oven $(1500 \mathrm{w})$, iron $(700$ $1000 \mathrm{w}$ ) and toaster $(750 \mathrm{w})$ consume more energy than that of other appliances [21]. 
Table 2. Households' Appliances

\begin{tabular}{|l|c|c|c|c|}
\hline Appliance Name & $\begin{array}{c}\text { Household having } \\
\text { appliances }\end{array}$ & $\begin{array}{c}\text { Percentage } \\
\text { (out of 141) }\end{array}$ & $\begin{array}{c}\text { Total appliance } \\
\text { in 141 household }\end{array}$ & $\begin{array}{c}\text { Appliances } \\
\text { per household }\end{array}$ \\
\hline Air Conditioners & 50 & 35.46 & 70 & 1.4 \\
\hline Washing Machine & 17 & 12.06 & 17 & 1 \\
\hline Freezers & 53 & 37.59 & 55 & 1.04 \\
\hline Refrigerators & 135 & 95.74 & 165 & 1.22 \\
\hline Geyser & 30 & 21.28 & 34 & 1.13 \\
\hline Microwave Oven & 57 & 40.43 & 59 & 1.03 \\
\hline Fan & 141 & 100.00 & 648 & 4.6 \\
\hline Light & 141 & 100.00 & 1266 & 8.98 \\
\hline Mixers & 26 & 18.44 & 26 & 1 \\
\hline Electronic Kettles & 12 & 8.51 & 13 & 1.08 \\
\hline Iron & 28 & 19.86 & 30 & 1.07 \\
\hline Rice Cookers & 39 & 27.66 & 39 & 1 \\
\hline Toasters & 8 & 5.67 & 8 & 1 \\
\hline Exhaust Hood & 8 & 5.67 & 8 & 1 \\
\hline Juicer & 16 & 11.35 & 18 & 1.13 \\
\hline Television & 137 & 97.16 & 178 & 1.3 \\
\hline Mobile & 131 & 92.91 & 512 & 3.9 \\
\hline Desktop Computer & 83 & 58.87 & 87 & 1.05 \\
\hline Laptop Computer & 63 & 44.68 & 85 & 1.35 \\
\hline Sound Box & 28 & 19.86 & 35 & 1.25 \\
\hline
\end{tabular}

\subsection{Energy Consumption in Different Income Levels}

An increasing trend of monthly energy consumption has been observed with higher household income (Figure 1). Energy consumption has steadily risen up to income level of BDT 51,000 to 60,000 falls slightly in the range of BDT 61,000 to 70,000 and remains stable between BDT 71,000 to 100,000 . Energy consumption increases sharply after exceeding the income level of more than 100,000 BDT per month. Higher income allows more usage of electronic appliances especially air conditioner, washing machine, refrigerators, toasters and computer.

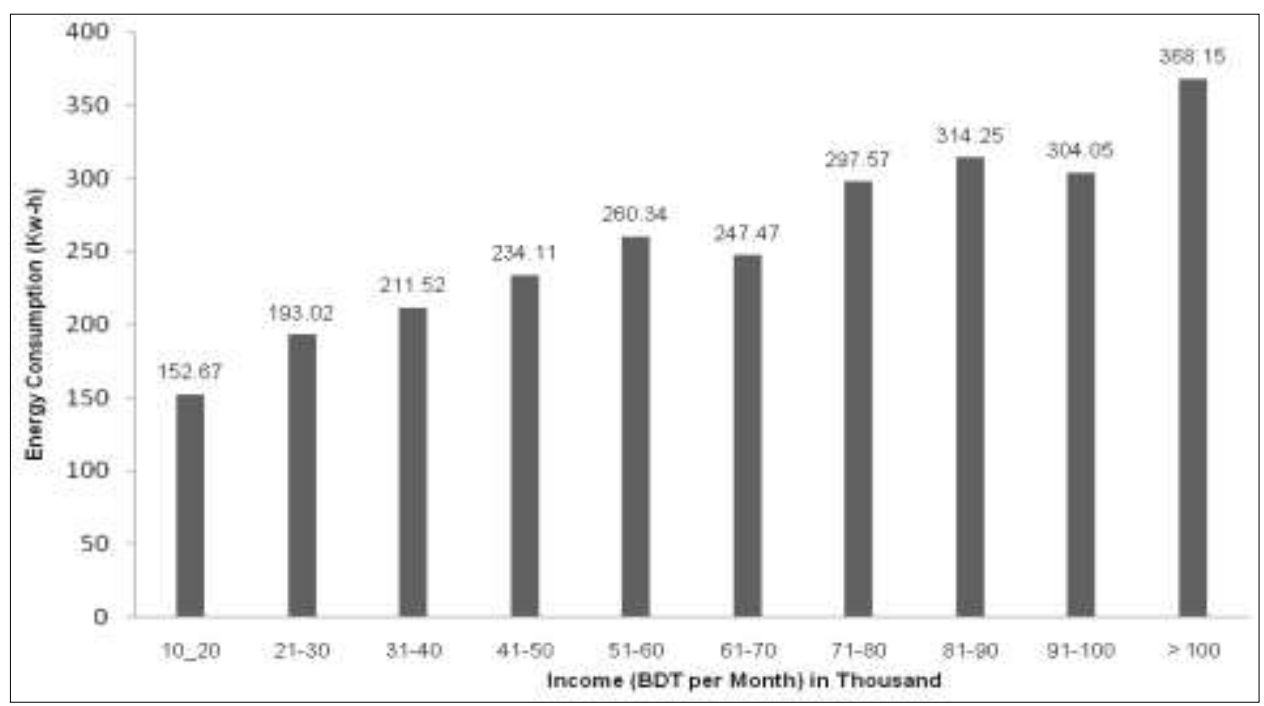

Figure 1. Energy Consumption among Different Income Groups 


\subsection{Household Member and Energy Consumption}

Energy consumption varies with the number of household member. Figure 6 shows that, single member household consume the lowest average unit of energy $(100.08 \mathrm{kw}-\mathrm{h})$ and households consist of seven or more members, on the other hand, consume the highest average unit of $293.93 \mathrm{kw}-\mathrm{h}$.

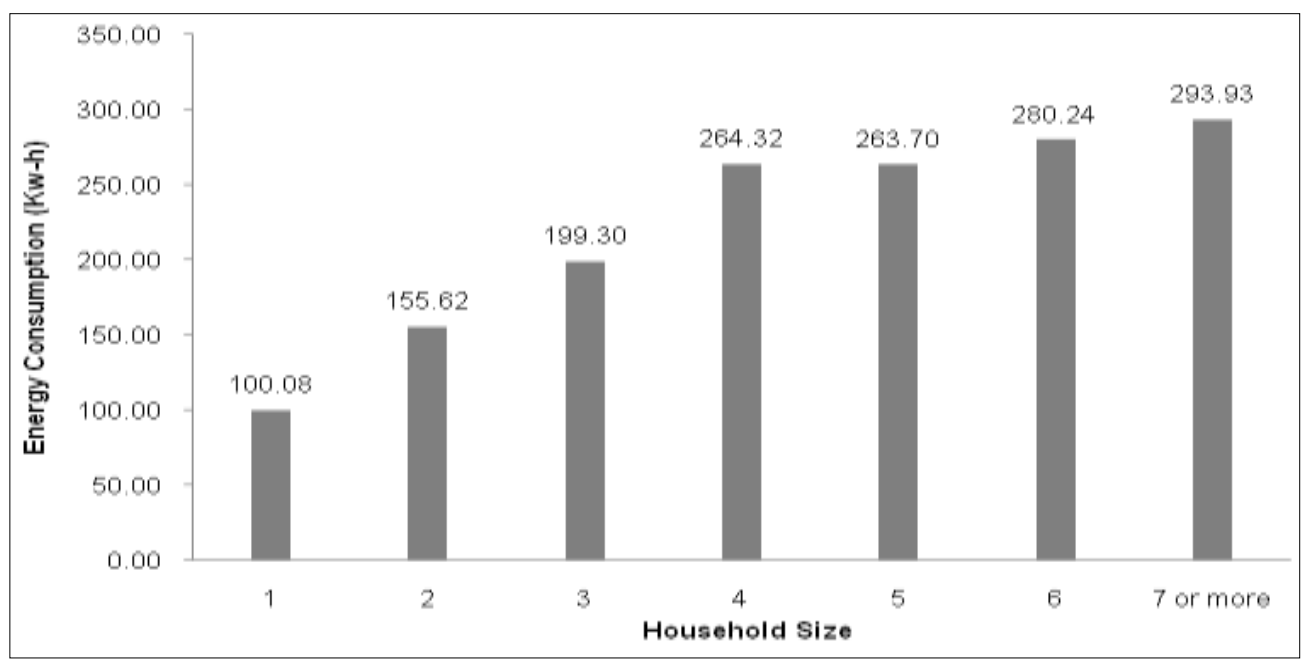

Figure 2. Energy Consumption in Different Household Size

A gradual increase in energy consumption has been observed within households comprising of one, two and three members. Energy consumption found almost similar in households of four and five members; however, households of six and seven or more members show a slightly increasing trend.

\subsection{Flat Size and Energy Consumption}

Figure 3 indicates that energy consumption is more in larger sized flat. The average monthly energy consumption is the lowest in flats of 54 and less than $54 \mathrm{~m}^{2}$ and highest in flats of $162 \mathrm{~m}^{2}$ and more.

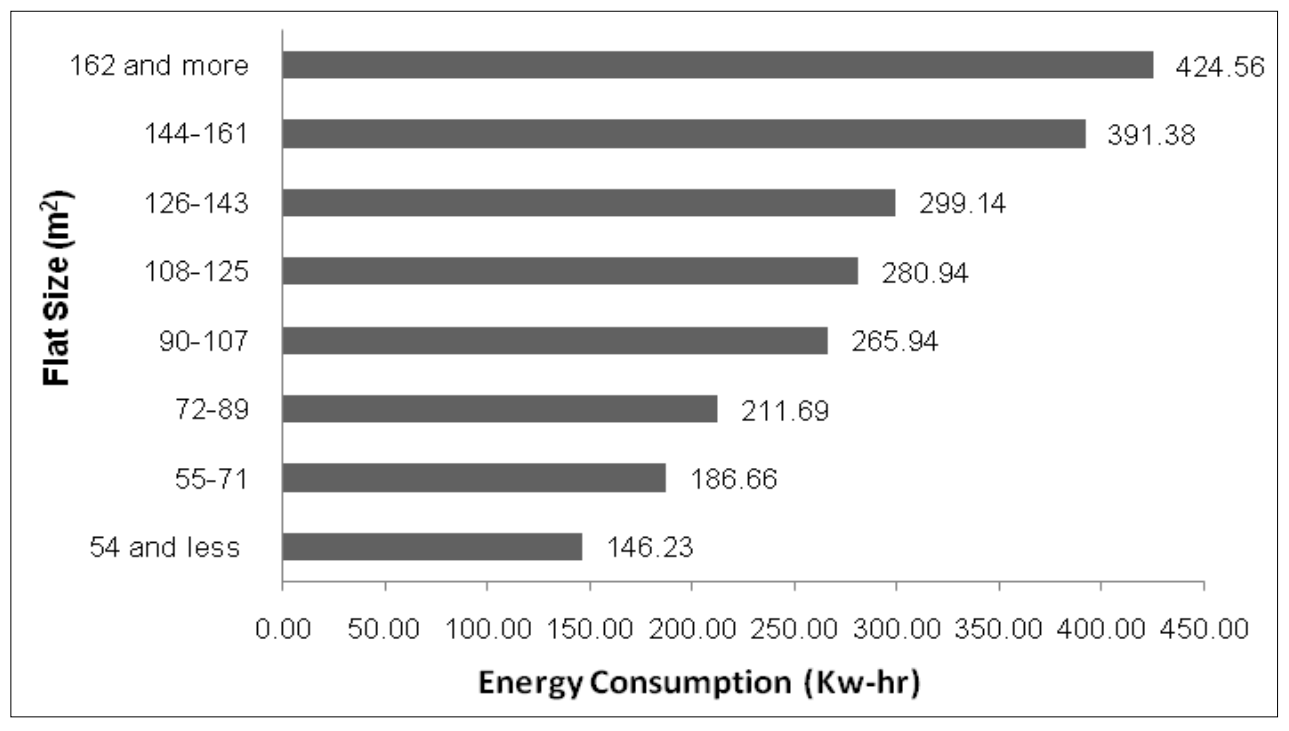

Figure 3. Energy Consumption in Different Flat Size 
Energy consumption progressively increase from 146.23 to $211.69 \mathrm{kw}-\mathrm{h}$ in flat size between 54 to $89 \mathrm{~m}^{2}, 265.94$ to $299.14 \mathrm{kw}-\mathrm{h}$ in 90 to $143 \mathrm{~m}^{2}$ sized flat. A sharp increase in energy consumption has been observed in flat sizes range between 1600 to $144 \mathrm{~m}^{2}$ and 162 to more than $162 \mathrm{~m}^{2}$.

\subsection{Window Area and Energy Consumption}

This is observed that, monthly average energy consumption forms an upward trend with the increase of window area (Figure 4). Usually large sized flats of Dhaka city have large window area and more appliances are used in these spaces.

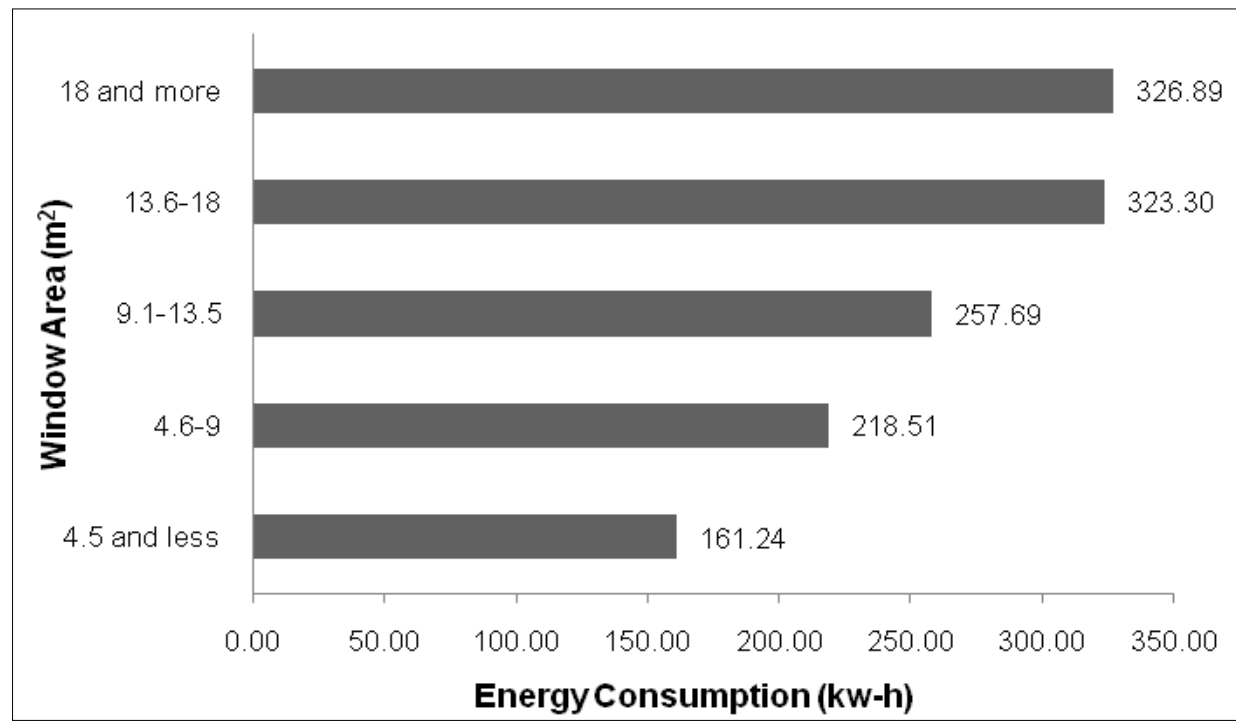

Figure 4. Energy Consumption in Different Window Area

Since smaller window area indicates smaller flat size and relatively less use of electronic appliances; energy consumption is also found less in such type of dwelling unit. A gradual increase is found indwelling units having window area ranges between $4.5 \mathrm{~m}^{2}$ and $13.5 \mathrm{~m}^{2}$. A sharp increase is observed in dwelling unit with window area of $13.6 \mathrm{~m}^{2}$ up to $18 \mathrm{~m}^{2}$.

\subsection{Relationships between Energy Consumption and Households' Characteristics}

Pearson correlation has been used to explore the strength of the relationship among variables, for example, annual average energy consumption, flat size, window area household size, income and number of appliances. Correlation reveals that, average yearly energy consumption is positively related with all the variables and all the relationships are significant $(\mathrm{p}<0.01)$ (Table 3$)$.

Among the variables, number of appliances, flat size and income influence the average annual energy consumption in greater extent ( $\mathrm{r}=0.663, \mathrm{r}=0.658$ and $\mathrm{r}=556$ respectively). Extended flat size implies with additional number and operating hours of appliances and thereby augments energy consumption. Besides, higher income allows more usage of electronic appliances with higher energy consumption rating especially air conditioner, Washing Machine, Refrigerators, Toasters, computer. 
Table 3. Correlation and Inter-correlation between Variables

\begin{tabular}{|c|c|c|c|c|c|c|}
\hline & 1 & 2 & 3 & 4 & 5 & 6 \\
\hline 1 & 1.00 & $.265^{\text {** }}$ & $.337^{\text {** }}$ & $.221^{\text {** }}$ & .097 & $.307^{\text {** }}$ \\
\hline 2 & $.265^{\text {** }}$ & 1.00 & $.488^{\text {** }}$ & $.551^{\text {** }}$ & $.352^{\text {** }}$ & $.556^{\text {** }}$ \\
\hline 3 & $.337^{\text {** }}$ & $.488^{\text {** }}$ & 1.00 & $.564^{\text {** }}$ & $.449^{\text {** }}$ & $.663^{\text {** }}$ \\
\hline 4 & $.221^{\text {** }}$ & $.551^{\text {** }}$ & $.564^{\text {** }}$ & 1.00 & $.560^{\text {** }}$ & $.658^{\text {** }}$ \\
\hline 5 & .097 & $.352^{\text {** }}$ & $.449^{\text {** }}$ & $.560^{\text {** }}$ & 1.00 & $.540^{\text {** }}$ \\
\hline 6 & $.307^{\text {** }}$ & $.556^{\text {** }}$ & $.663^{\text {** }}$ & $.658^{\text {** }}$ & $.540^{\text {** }}$ & 1.00 \\
\hline
\end{tabular}

**. Correlation is significant at the 0.01 level (2-tailed).

Notes: $1=$ household size, $2=$ income, $3=$ number of appliances, $4=$ flat size, $5=$ window area, $6=$ average annual energy consumption

On the contrary, Energy consumption is comparative less affected by household size and window area $(r=0.307$ and $r=0.540$ respectively). Generally, energy consumption does not fluctuate too much within the households of similar living standards.

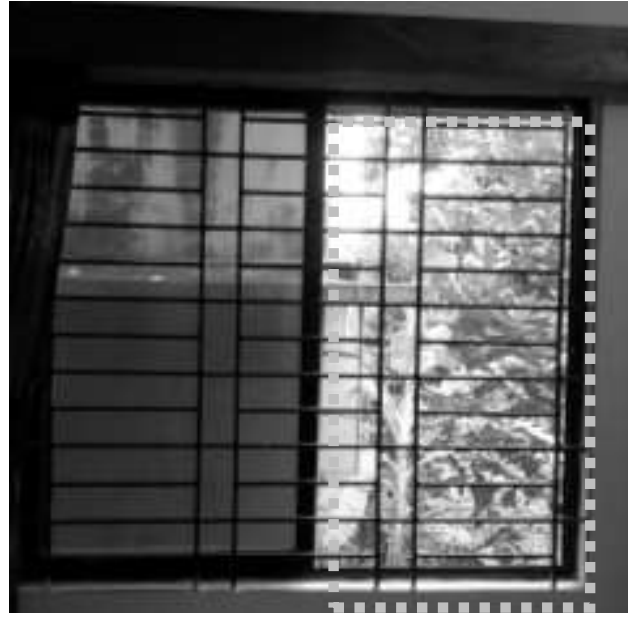

(a)

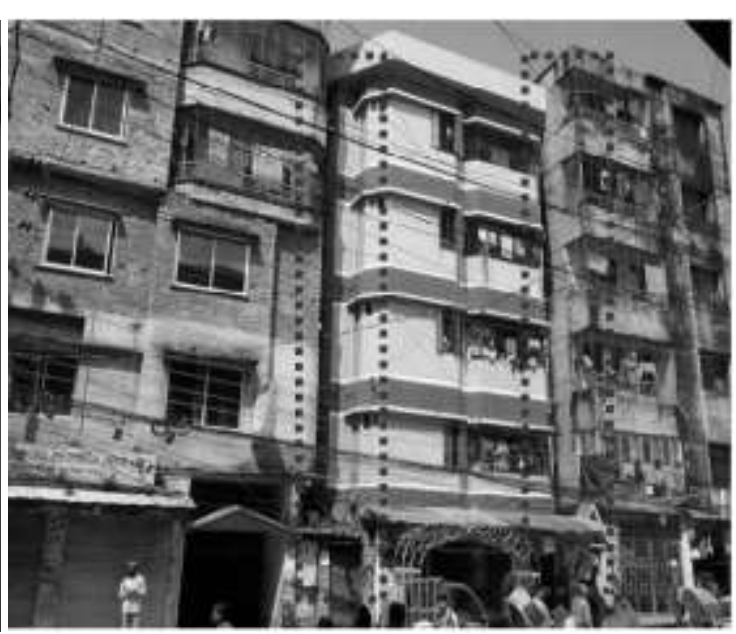

(b)

Figure 5. (a) Half Opening of Window and (b) Inadequate Space between Buildings

Usually larger window area allows more daylight and air flow within the buildings and thereby reduce energy consumption. However, a different scenario is found in case of Dhaka City. Field observations indicates that, being conservative in socio-cultural domain, windows of residential buildings in Dhaka city remain closed or otherwise screened. In addition, maximum windows are made of $5 \mathrm{~mm}$ thickness tinted glass with aluminum frames and the openings of these windows are limited to 50 per cent of the window size (Figure 5.a) [10]. Inadequate spaces between buildings also hinder natural ventilation (Figure 5.b).

The thermal conductivity of aluminum and glass are $204 \mathrm{~W} / \mathrm{m} \mathrm{k}$ and $1.1 \mathrm{~W} / \mathrm{m} \mathrm{k}$ respectively [22 and 23]. In addition, the U-value of window is 6; which is much higher than the prescribed level of energy efficient window. The lower the U-value the better the insulation properties of the window, the better it is at keeping the heat or cold out [24]. Higher thermal conductivity and U-value of window materials increase thermal mass of buildings. Thus, larger window area, therefore, is contributing in more energy consumption. 


\section{Conclusion}

This study reveals that, the effects of households' socio-economic characteristics on energy consumption are more significant than building geometric features in Dhaka city. For a comfortable living and possessing an uplifted social status increased numbers of appliances are used by many households and thus increase the energy consumption. Additionally, larger flat size requires more energy to keep that functional. Energy consumption increases with the increase of window size, is one interesting finding of this study. Limited opening, usage of screen and thermal properties of window materials results in augmented energy use. Results of the study indicate that socio-economic characteristics of households should be critically considered in designing energy efficient residential buildings in Dhaka city.

\section{Acknowledgement}

The authors express gratitude to Salman Jahangir, graduate student, Session: 20112012, Department of Urban and Regional Planning, Jahangirnagar University, for his sincere contribution in data collection and Professor Dr. Shoichi Kojima, Graduate School of Science and Engineering, Saga University, Japan for his kind intellectual support. Cordial cooperation of Professor Dr. Sheikh Mohammed Rafiul Huque, Institute of Business Administration and Azizur Rahman, Assistant Professor, Department of Statistics, Jahangirnagar University are duly appreciated by the authors.

\section{References}

[1] UN-Habitat, "Urban planning for city leaders", 978-92-1-132505-8, Nairobi, Kenya, (2013).

[2] World Bank, "Cities and climate change: an urgent agenda", vol.10, (2010).

[3] W. E. Rees, "Cities as dissipative structure: global change and the vulnerability of cities," in M. P. Weinstein and R. E.Turner, (Eds.), Sustainability Science: the Emerging Paradigm and the Urban Environment. Springer, New York, (2012).

[1] UN-Habitat, Energy, http://unhabitat.org/urban-themes/energy, (2016).

[2] Ma Xianrui, Xia Wang, Du Yongjie, Cai Weiguang, "Relationship Analysis between Urbanization and Building Energy Consumption in China Based on a Structural Equation Model," Computer Modelling \& New Technologies, vol. 18, no.12C, (2014), pp.994-1002.

[3] U.S. Energy Information Administration, "International energy outlook 2013, (2013).

[4] United Nations Environment Programme (UNEP) - SBCI, Unep.org. (2017).

[5] D.Ürge-Vorsatz, N. Eyre, P. Graham, D. Harvey, E. Hertwich, Y. Jiang, C. Kornevall, M. Majumdar, J. E. McMahon, S. Mirasgedis, S. Murakami, and A. Movikova, "Energy end-use: building. in global energy assessment- toward a fustainable future," Cambridge University Press, Cambridge, UK and New York, NY, USA and the International institute for Applied System Analysis, Laxenburg, Austria, (2012), pp. 649-760.

[6] M. F. Touchie, C. Binkley, and K. D. Pressnail, "Correlating energy consumption with multi-unit residential building characteristics in the city of Toronto," Energy \& Buildings, vol.66, (2013), pp.648656.

[7] T. Ahsan, V. Soebarto, and T. Williamson, "Key predictors of annual electricity use in high-rise residential apartments in Dhaka, Bangladesh," Proceedings of the $48^{\text {th }}$ International Conference of the Architectural Science Association, Genoa, Italy, (2014), December 10-14.

[8] H. Liu, and S. Kojima, "A survey on the energy consumption and thermal satisfaction in urban residential households in hot-Summer and cold-winter zone in China," Proceedings of the International Graduate Research Conference, Chiang Mai University, Thailand, (2015), December 11.

[9] T. M. Haider and M. Ahmed, "Energy consumption and urban texture: a case study of Dhaka", The Daily Star, (2016).

[10] Mondal, M. A. H. and M. Denich. "Assessment of renewable energy resources potential for electricity generation in Bangladesh," Renewable and Sustainable Energy Reviews, vol.14 no 8, (2010), pp.24012413.

[11] Dhaka Electric Supply Company Limited (DESCO), “Annual report”, DESCO, Dhaka,(2016).

[12] UN-HABITAT, State of the World's Cities 2008/2009, harmonious cities, London: Earthscan in the UK and USA, (2008), pp. 164-174. 
[13] K. Bahauddin, M. Rahman, and F.Ahmed, "Towards urban city with sustainable buildings: a model for Dhaka city, Bangladesh. Environment And Urbanization Asia, vol.5, no.1, (2014), pp. 119-130. http://dx.doi.org/10.1177/0975425314521531.

[14] Strømann-Andersen, J and Sattrup, P.A., "The urban canyon and building energy use: Urban density versus daylight and passive solar gains, Energy and Buildings, vol.43, no.8, (2011), 2011-2020.

[15] J. Pallant, "SPSS survival manual: a step by step guide to data analysis using SPSS", Allen \& Unwin, Australia, (2011).

[16] D. Gall, R. Borg, and P. Gall, Educational Research: An Introduction, NY: Longman Publishers USA, (1996).

[17] S. Chowdhury, R. Alam and S. Paul, "Daylight performance and energy consumption in a simple room of residential building in Dhaka city Bangladesh", Proceedings of the 28th International Symposium on Automation and Robotics in Construction, ISARC, Seoul, Korea, (2011), June 29-July 2.

[18] Dhaka Electric Supply Company Limited (DESCO), DESCO appliance calculator, www.desco.org.bd/?page=bill-calculator, (2017).

[19] The Engineering Toolbox, Retrieved from: http://www.engineeringtoolbox.com/thermal-conductivitymetals-d_858.html, (2017).

[20] Engineers Edge, , Retrieved from: http://www.engineersedge.com/heat_transfer/thermal-conductivitymetals-alloys.htm, (2017).

[21] Efficient Window, "Measuring performance: U-Factor", Retrieved from: http://www.efficientwindows.org/ufactor.php, (2017).

[22] Pearson Correlation, http://pages.intnet.mu/cueboy/education/notes/statistics/pearsoncorrel.pdf, (2018).

\section{Authors}

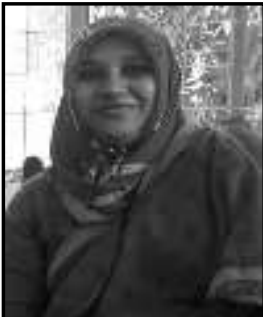

Dr. Anisha Noori Kakon, she is an Associate Professor in the Department of Urban and Regional Planning at Jahangirnagar University, Savar, Dhaka, Bangladesh. She completed her $\mathrm{PhD}$ degree in the Department of Architecture and Civil Engineering, Saga University, Japan. Her research interests focus on Urban Planning, Climate-sensitive Urban Planning and Design, Housing and Environmental Planning.

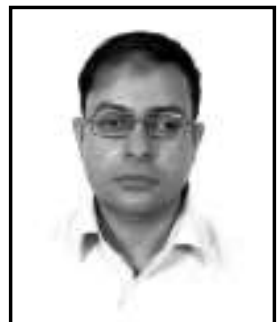

Farhadur Reza, he is serving as an Assistant Professor in the Department of Urban and Regional Planning, Jahangirnagar University, Dhaka, Bangladesh. He obtained Master Degree in Urban and Regional Planning from Jahangirnagar University. His research interest lies in application of Quantitative Techniques in the field of Urban Planning, Environmental Management and Planning, Transportation Planning and Time Series Analysis. 